pathway for people with lung cancer in the UK in order to maximise the number of people who can receive the currently available effective treatments, including potentially curative treatment with surgery or radical radiotherapy. This in turn should then mean that the survival of people with lung cancer in the UK increases to match the best in Europe. This would represent a significant step forward for people with lung cancer in the UK.

Funding RBH's post is funded by the British Lung Foundation via an unrestricted grant from GlaxoSmithKline.

Competing interests None.

Provenance and peer review Commissioned; not externally peer reviewed.

Thorax 2010;65:756-758.

doi:10.1136/thx.2010.145961

\section{REFERENCES}

1. Office for National Statistics. Mortality statistics: deaths registered in 2008. DR 2009.

2. Peto R, Darby S, Deo H, et al. Smoking, smoking cessation, and lung cancer in the UK since 1950: combination of national statistics with two casecontrol studies. BMJ 2000;321:323-9.

3. Raw M, McNeill A, West R. Smoking cessation guidelines for health professionals. A guide to effective smoking cessation interventions for the health care system. Thorax 1998;53(Suppl 5, Pt 1): S1-19.
4. West R, McNeill A, Raw M. Smoking cessation guidelines for health professionals: an update. Thorax 2000;55:987-99.

5. Tobacco Advisory Group of the Royal College of Physicians. Harm reduction in nicotine addition: helping people who can't quit. London: Royal College of Physicians, 2007.

6. World Health Organization. WHO framework convention on tobacco control. Geneva: World Health Organization, 2003.

7. van Klaveren RJ, Oudkerk $M$, Prokop $M$, et al. Management of lung nodules detected by volume CT scanning. N Engl J Med 2009;361:2221-9.

8. Blanchon T, Brechot JM, Grenier PA, et al. Baseline results of the Depiscan study: a French randomized pilot trial of lung cancer screening comparing low dose CT scan (LDCT) and chest X-ray (CXR). Lung Cancer 2007;58:50-8

9. Pedersen JH, Ashraf H, Dirksen A, et al. The Danish randomized lung cancer $\mathrm{CT}$ screening trial: overall design and results of the prevalence round. J Thorac Oncol 2009:4:608-14.

10. Infante M, Cavuto S, Lutman FR, et al. A randomized study of lung cancer screening with spiral computed tomography: three-year results from the DANTE trial. Am J Respir Crit Care Med 2009;180:445-53.

11. Gohagan JK, Marcus PM, Fagerstrom RM, et al. Final results of the Lung Screening Study, a randomized feasibility study of spiral CT versus chest X-ray screening for lung cancer. Lung Cancer 2005;47:9-15

12. Lopes Pegna A, Picozzi G, Mascalchi M, et al. Design, recruitment and baseline results of the ITALUNG trial for lung cancer screening with lowdose CT. Lung Cancer 2009;64:34-40.

13. Infante MV, Pedersen JH. Screening for lung cancer: are we there yet? Curr Opin Pulm Med 2010;16:301-6.
14. Black C, de Verteuil R, Walker S, et al. Population screening for lung cancer using computed tomography, is there evidence of clinical effectiveness? A systematic review of the literature. Thorax 2007;62:131-8

15. Detterbeck $\mathbf{F}$. The fruits of our efforts: time for a different view of lung cancer and CT screening. Thorax 2009;64:465-6.

16. Chapman CJ, Murray A, McElveen JE, et al. Autoantibodies in lung cancer: possibilities for early detection and subsequent cure. Thorax 2008;63:228-33.

17. Mazzone PJ, Hammel J, Dweik R, et al. Diagnosis of lung cancer by the analysis of exhaled breath with a colorimetric sensor array. Thorax 2007;62:565-8

18. Holmberg L, Sandin F, Bray F, et al. National comparisons of lung cancer survival in England, Norway and Sweden 2001-2004: differences occur early in follow-up. Thorax 2010;65:436-41.

19. Imperatori A, Harrison RN, Leitch DN, et al. Lung cancer in Teesside (UK) and Varese (Italy): a comparison of management and survival. Thorax 2006:61:232-9.

20. Corner J, Hopkinson J, Fitzsimmons D, et al. Is late diagnosis of lung cancer inevitable? Interview study of patients' recollections of symptoms before diagnosis. Thorax 2005;60:314-19.

21. Smith SM, Campbell NC, MacLeod U, et al. Factors contributing to the time taken to consult with symptoms of lung cancer: a cross-sectional study. Thorax 2009;64:523-31.

22. Hamilton W, Peters TJ, Round A, et al. What are the clinical features of lung cancer before the diagnosis is made? A population-based case-control study. Thorax 2005;60:1059-65

23. Suckling R. Early lung cancer intervention in Doncaster. Doncaster: Public Health Department, 2008.

\title{
Asthma: improved understanding and insights into the challenges of achieving asthma control
}

G lan Town, ${ }^{1} \mathrm{~J}$ Mark Fitzgerald ${ }^{2}$

Asthma articles were among the most frequently cited and downloaded items from the Thorax website. The BTS-Sign Asthma Guidelines topped the list, indicating the important role Thorax has played in supporting the respiratory community and the British Thoracic Society in particular.

One of the more important articles covering asthma epidemiology summar-

\footnotetext{
${ }^{1}$ University of Canterbury, Christchurch, New Zealand ${ }^{2}$ UBC Centre for Lung Health, University of British Columbia, Vancouver, Canada
}

Correspondence to J Mark Fitzgerald, UBC Centre for Lung Health, University of British Columbia, Vancouver, Canada; mark.fitzgerald@vch.ca ised the findings of Phase III of the International Study of Asthma and Allergies in Children (ISAAC). ${ }^{1}$ This study, undertaken in some 106 centres in 56 countries, compared the prevalence of asthma symptoms $5-10$ years after the original surveys. In 6- to 7-year olds, asthma prevalence (wheeze in the last 12 months) was $11.6 \%$ and in the 13- to 14-year-old children $13.7 \%$. Comparing trends over time, prevalence had fallen in many western countries but had increased in some other countries including Eastern Europe and parts of Asia. These important ecological data triggered much discussion about the likely causes of the observed trends but failed to generate a unifying hypothesis that could be tested. Thorax also carried a number of other papers generated by the ISAAC study, among the more interesting of which examined the effect of diet on asthma and allergic sensitisation. ${ }^{2}$ This report, based on ISAAC Phase II data, examining $>50000$ children demonstrated that fruit intake was associated with a lower prevalence of current wheeze and conferred a lifetime protective effect, as did consumption of vegetables and fish. We have high expectations that the enormous epidemiological database held by the ISAAC researchers will continue to shed light on risk factors and inform protective strategies.

Asthma genetics was a very hot topic, and interest peaked over the ADAMB3 story. A frenzy of interest ensued and this was touted as a major breakthrough in our understanding. With the benefit of hindsight, the real impact was modest. Breaking initially in Nature in $2002,{ }^{3}$ the gene encoding $\mathrm{ADisintegrin}$ and Metalloprotease 33 , on chromosome $20 \mathrm{p} 13$, was identified by positional cloning. Thorax carried an editorial on the topic the following year, ${ }^{4}$ which noted that this 
gene confers susceptibility to asthma and bronchial hyper-responsiveness possibly through a role in airway remodelling. A meta-analysis published in 2005 by Blakey et $a l^{5}$ reviewed studies undertaken in Icelandic and UK populations and demonstrated that the $\mathrm{F}+1$ and $\mathrm{ST}+7$ variants were significantly associated with asthma and might potentially account for 50000 excess asthma cases in the UK. Commenting further, an editorial by Holgate and Holloway ${ }^{6}$ noted that the mode of influence was probably 'complex involving gene-gene or gene-environment interactions' and speculated that one mechanism might be via impairment of lung function in early life, thereby increasing the risk of asthma developing later. They boldly asserted that the new era of translational science will further elucidate the mystery! We are left with the fact that asthma seems to run in families.

Throughout the 1990s there was a very strong emphasis on the role of the eosinophil in the pathogenesis of asthma. Informed by many lavage, biopsy and, later, induced sputum studies, the eosinophil loomed large in Thorax papers. Relationships between exhaled nitric oxide and eosinophil count were also explored. However, in thinking about what has come to be termed 'difficult asthma', questions about the model emerged and thoughts turned to the role of the neutrophil as an effector cell in more serious steroid-resistant cases. In an editorial in 2005, Kamath and colleagues put the case that in non-atopic and severe asthma phenotypes the neutrophil is the more important cell. ${ }^{7}$ Evidence cited included the role of the neutrophil in nocturnal asthma, smokers, occupational asthma and some asthma exacerbations. Related to this topic came a study published by Berry et al reporting sputum and biopsy data from patients with what they termed non-eosinophilic asthma. ${ }^{8}$ In a group of 11 subjects they found an absence of eosinophils and normal subepithelial layer thickness. There was little improvement in $\mathrm{PC}_{20}$ methacholine or asthma quality of life following 8 weeks of inhaled corticosteroids (ICS). To add weight to the story, Nadif et al reported significant heterogeneity of asthma according to blood inflammatory patterns. 9 They reported data on 381 subjects with asthma from France and noted that just over half had a 'low eosinophil' pattern ( $<250$ eosinophils/ $\mathrm{mm}^{3}$ ) and among those were a group termed 'neutrophil high' which was asso- ciated with a reduced frequency of atopy as judged by skin prick test. More recently Cowan et al reported the effects of steroid treatment in inflammatory cell subtypes in asthma. ${ }^{10}$ They examined subjects during steroid withdrawal over 28 days and found that loss of control was associated with an eosinophilic pattern in two-thirds of subjects. When ICS were reintroduced, a small number of subjects $(n=5)$ developed the neutrophilic pattern, raising the question (not for the first time) that steroids may lead to neutrophil attraction through, for example, increases in interleukin 8 (IL-8). In drawing conclusions from this work and similar, Boulet opines that previous assumptions about the role of the neutrophil in subjects taking ICS need to be re-examined. ${ }^{11}$

In parallel with these papers focusing on the epidemiology and pathogenesis of asthma, a number of studies were published which showed significant care gaps in the management of asthma. This was particularly striking in the study by Blais and Beauchesne which showed that even in patients discharged from the Emergency Department, after an acute asthma attack, there was poor adherence to the use of ICS in the subsequent 6 months. ${ }^{12}$ Among adult asthma patients with chronic asthma similar poor adherence to treatment was shown. On a more positive note, Gibson and Howell showed that a structured written action plan consistently improved health outcomes. ${ }^{13}$ Traditionally we have assumed that health workers need to take the lead in providing asthma education, but in an interesting study Partridge et al showed that lay people could deliver an asthma education programme as effectively as healthcare providers. ${ }^{14}$ Given the imbalance between the need to deliver asthma education and the available human resources, this model for the delivery of asthma education is an exciting new opportunity. In conclusion, when these elements are combined in a national asthma campaign it is possible to have a significant effect on healthcare utilisation with such an approach. More specifically, Haahtela et al showed that in Finland, a dramatic reduction in hospitalisations for acute asthma could be achieved. ${ }^{15}$ Empowered by these exciting results, the Global Initiative in Asthma (GINA) have put forward a 5-year challenge to reduce hospitalisations for acute asthma by $50 \%{ }^{16}$

In conclusion, research published in Thorax over the last 6 years has improved our understanding of the epidemiology and pathogenesis of asthma. Although there are still many gaps in our knowledge, many of the published papers have had a direct impact on patient care through innovative strategies to improve asthma outcomes.

\section{Competing interests None.}

Provenance and peer review Commissioned; not externally peer reviewed.

Thorax 2010;65:758-759.

doi:10.1136/thx.2010.146274

\section{REFERENCES}

1. Pearce N, Aït-Khaled N, Beasley R, et al. Worldwide trends in the prevalence of asthma symptons: phase III of the International Study of Asthma and Allergies in Childhood (ISAAC). Thorax 2007;62:758-66.

2. Nagel G, Weinmayr G, Kleiner A, et al. Effect of diet on asthma and allergic sensation in the International Study on Allergies and Asthma in Childhood (ISAAC) Phase Two. Thorax 2010;65:516-22.

3. Van Eerdewegh $\mathbf{P}$, Little R-D, Dupuis J, et al. Association of the ADAM-33 gene with asthma and bronchial hyper-responsiveness. Nature 2002; 418:426-30.

4. Holgate S-T, Davies D-E, Murphy G, et al. ADAM33: just another asthma gene or a breakthrough in understanding the origins of bronchial hyperresponsiveness? Thorax 2003;58:466-9.

5. Blakey J, Halapi E, Bjornsdottir U-S, et al. Contribution of ADAM33 polymorphisms to the population risk of asthma. Thorax 2005; 60:274-6.

6. Holgate S-T, Holloway J-W. Is big beautiful? The continuing story of ADAM33 and asthma. Thorax 2005;60:263-4.

7. Kamath A-V, Pavord I-D, Ruparelia P-R, et al. Is the neutrophil the key effector cell in severe asthma? Thorax 2005:60:529-30.

8. Berry M, Morgan A, Shaw D-E, et al. Pathological features and inhaled corticosteroid response of eosinophilic and non-eosinophilic asthma. Thorax 2007;62:1043-9.

9. Nadif R, Siroux V, Oryszczyn M-P, et al. Heterogeneity of asthma according to blood inflammatory patterns. Thorax 2009;64:374-80.

10. Cowan D-C, Cowan J-O, Palmay R, et al. Effects of steroid therapy on inflammatory cell subtypes in asthma. Thorax 2010;65:384-90.

11. Boulet L-P. Effects of steroid therapy on inflammatory cell subtypes in asthma. Thorax 2010;65:374-6

12. Blais $\mathbf{L}$, Beauchesne M-F. Use of inhaled corticosteroids following discharge from an emergency department with acute asthma. Thorax 2004;59:943-7.

13. Gibson PG, Powell H. Written action plans for asthma: an evidence based review of the key components. Thorax 2004;59:94-9.

14. Partridge MR, Caress A-L, Brown $C$, et al. Can lay people deliver asthma self-management education as effectively as primary care based practice nurses? Thorax 2008;63:778-83.

15. Haatela T, Tuomisto LE, Pietinalho A, et al. A 10 year asthma programme in Finland: a major change for the better. Thorax 2006;61:663-70.

16. http://www.GINA.com. 